\title{
Commentary: Are microRNAs the new wave of biomarkers in congenital heart surgery?
}

\author{
Mauro Lo Rito, MD
}

\author{
From the Department of Congenital Cardiac Surgery, IRCCS Policlinico San Donato, San Donato Milanese, Italy. \\ Disclosures: Author has nothing to disclose with regard to commercial support. \\ Received for publication April 17, 2019; accepted for publication April 17, 2019; available ahead of print May 31, \\ 2019. \\ Address for reprints: Mauro Lo Rito, MD, Department of Congenital Cardiac Surgery, IRCCS Policlinico San \\ Donato, San Donato Milanese, Italy (E-mail: mauro.lorito@gmail.com). \\ J Thorac Cardiovasc Surg 2020;159:1543 \\ $0022-5223 / \$ 36.00$ \\ Copyright (c) 2019 by The American Association for Thoracic Surgery \\ https://doi.org/10.1016/j.jtcvs.2019.04.058
}

The search for new biomarkers is characterized by initial enthusiastic rise in interest followed by downs mainly due to the inability of the new discoveries to be translated to everyday clinical practice. In cardiac surgery, several claims have been made regarding new biomarkers but very few (eg, troponin or pro-brain natriuretic peptide) have been actually adopted widely in clinical practice, especially in the field of congenital abnormalities. The microRNAs have been studied for almost a decade and have shown characteristics that make them good candidates to be used as biomarkers. Cells use microRNAs as a posttranscriptional regulation mechanism and the entire process is highly preserved. ${ }^{1}$ We have to imagine that microRNAs are the official common language that cells use to speak with foreign targets in response to heterogeneous biological processes. ${ }^{2}$ In particular, a group of microRNAs is induced by hypoxic insult. ${ }^{3,4}$ Specifically, in acquired myocardial ischemia, microRNA-1 (miR-1 $)^{5}$ seems to be a reliable biomarker. Stoica and colleagues ${ }^{6}$ tackle the lack of biomarkers in congenital cardiac surgery with their study. They evaluate miR-1 for prediction of adverse postoperative outcome in a pediatric intensive care unit. They found a significant increase in miR-1 after the operation compared with the preoperative baseline values and its rise correlates with aortic cross-clamp duration. Augmented level of miR1 was also associated with prolonged intensive care unit stay, high inotropic support, and ventilation index. All of these findings make miR-1 an interesting potential biomarker. In fact, it could be used to identify patients who may experience more complicated postoperative courses-although there is still a long way to go, as acknowledged by the authors. A limitation to using miR-1 as a biomarker may be related to the fact it is mainly released by 3 cardiovascular compartments-myocytes, vascular cells, and smooth muscle cells_-and its expression is modulated by hypoxia. All 3 components experience some degree of relative hypoxia during heart surgery utilizing cardiopulmonary bypass due to complex mechanisms

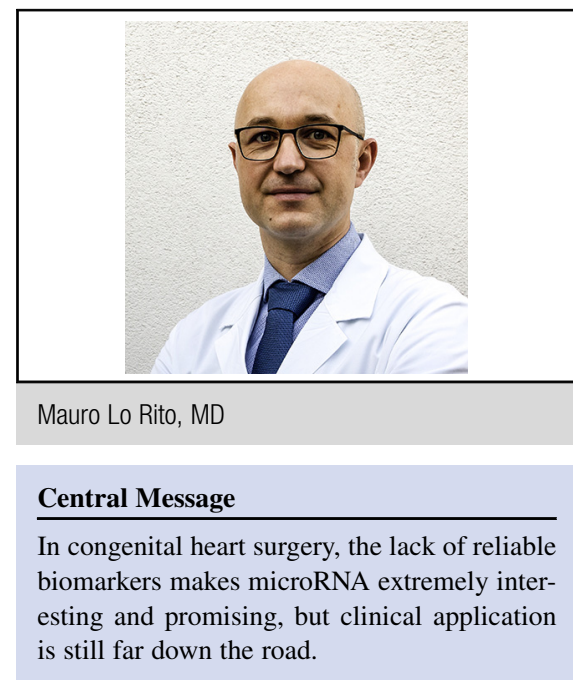

See Article page 1532.

that take place when there is a discrepancy between oxygen delivery and tissue/organ demands. The more complex is the surgical repair, the longer will be the hypoxic insult related to aortic cross-clamp; therefore, miR-1 may become a tautologic biomarker in that it will indicate what we already know by clinical experience. Several other points have to be understood before miR-1 becomes a biomarker because it may be an expression of true damage or it may be only the manifestation of a patient having been placed on cardiopulmonary bypass with aortic cross-clamp. We need a way to evaluate surgical and cardiopulmonary bypass strategies to minimize hypoxic insult to the body, thus improving patient care and outcomes. But we are not there yet.

\section{References}

1. Remsburg C, Konrad K, Sampilo NF, Song JL. Analysis of microRNA functions. Methods Cell Biol. 2019;151:323-34.

2. Mott JL, Mohr AM. Overview of microRNA biology. Semin Liver Dis. 2015:35:3-11.

3. Bandara KV, Michael MZ, Gleadle JM. MicroRNA biogenesis in hypoxia MicroRNA. 2017;6:80-96.

4. Greco S, Zaccagnini G, Voellenkle C, Martelli F. microRNAs in ischaemic cardiovascular diseases. Eur Heart J Suppl. 2016;18(Suppl E):E31-6.

5. D'Alessandra Y, Devanna P, Limana F, Straino S, Di Carlo A, Brambilla PG, et al Circulating microRNAs are new and sensitive biomarkers of myocardial infarction. Eur Heart J. 2010;31:2765-73.

6. Stoica S, Dorobantu D, Vardeu A, Biglino G, Ford KL, Bruno DV, et al MicroRNAs as potential biomarkers in congenital heart surgery. J Thorac Cardiovasc Surg. 2020;159:1532-40.e7. 